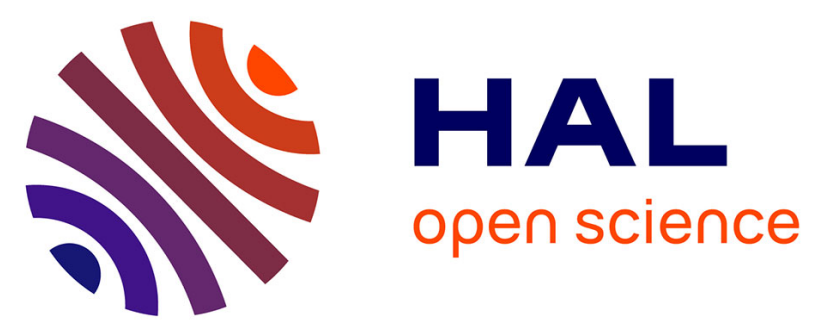

\title{
HCFC-22 emissions at global and regional scales between 1995 and 2010: Trends and variability
}

\author{
A. Fortems-Cheiney, F. Chevallier, M. Saunois, I. Pison, P. Bousquet, C.
}

Cressot, H. Wang, Y. Yokouchi, F. Artuso

\section{To cite this version:}

A. Fortems-Cheiney, F. Chevallier, M. Saunois, I. Pison, P. Bousquet, et al.. HCFC-22 emissions at global and regional scales between 1995 and 2010: Trends and variability. Journal of Geophysical Research: Atmospheres, 2013, 118 (13), pp.7379-7388. 10.1002/JGRD.50544 • hal-02954506

\section{HAL Id: hal-02954506 https://hal.science/hal-02954506}

Submitted on 8 Oct 2020

HAL is a multi-disciplinary open access archive for the deposit and dissemination of scientific research documents, whether they are published or not. The documents may come from teaching and research institutions in France or abroad, or from public or private research centers.
L'archive ouverte pluridisciplinaire HAL, est destinée au dépôt et à la diffusion de documents scientifiques de niveau recherche, publiés ou non, émanant des établissements d'enseignement et de recherche français ou étrangers, des laboratoires publics ou privés. 


\title{
HCFC-22 emissions at global and regional scales between 1995 and 2010: Trends and variability
}

\author{
A. Fortems-Cheiney, ${ }^{1}$ F. Chevallier, ${ }^{1}$ M. Saunois,${ }^{1}$ I. Pison, ${ }^{1}$ P. Bousquet, ${ }^{1}$ C. Cressot, ${ }^{1}$ \\ H. J. Wang, ${ }^{2}$ Y. Yokouchi, ${ }^{3}$ and F. Artuso ${ }^{4}$ \\ Received 21 December 2012; revised 22 May 2013; accepted 2 June 2013; published 8 July 2013.
}

[1] HCFC-22 ( $\mathrm{CHClF}_{2}$, chlorodifluoromethane) is an ozone-depleting substance, the consumption of which is controlled under the Montreal Protocol. Within a Bayesian inversion framework, we use measurements of HCFC-22 atmospheric concentrations to constrain estimates of HCFC-22 emissions, at the grid point $3.75^{\circ} \times 2.5^{\circ}$ and 8 day resolution, from January 1995 to December 2010. Starting from a new gridded bottom-up inventory which is then optimized, our method shows continuously rising global emissions, from $182 \pm 11 \mathrm{Gg}$ in 1995 to the maximum of $410 \pm 9 \mathrm{Gg}$ in 2009 . This is mainly due to an increase of emissions in developing regions, particularly in Eastern Asia, and occurs despite the current phase-out in developed countries. The high temporal resolution of our inversion ( 8 day) allows to reveal some of the emission seasonality, the global posterior sources ranging from $25 \mathrm{Gg} /$ month in November to $42 \mathrm{Gg} / \mathrm{month}$ in July, for example, in 2010.

Citation: Fortems-Cheiney, A., F. Chevallier, M. Saunois, I. Pison, P. Bousquet, C. Cressot, H. J. Wang, Y. Yokouchi, and F. Artuso (2013), HCFC-22 emissions at global and regional scales between 1995 and 2010: Trends and variability, J. Geophys. Res. Atmos., 118, 7379-7388, doi:10.1002/jgrd.50544.

\section{Introduction}

[2] Chlorodifluoromethane $\left(\mathrm{CHClF}_{2}\right)$, commonly called HCFC-22, is a gas of purely anthropogenic origin. Used as a refrigerant in the air-conditioning and refrigeration industry, as a component in foam blowing and as a chemical feedstock in the manufacture of synthetic polymers, HCFC-22 is the most abundant of the hydrochlorofluorocarbons measured in the atmosphere [O'Doherty et al., 2004; Montzka et al., 2009; Saikawa et al., 2012]. Mainly removed from the atmosphere by its reaction with hydroxyl radicals $(\mathrm{OH})$, it has a lifetime of about 11.9 years [Montzka et al., 2011; Saikawa et al., 2012]. There exist two other sinks for HCFC-22: an oceanic sink and one from a reaction with chlorine $(\mathrm{Cl})$. They are limited to only a few percent of that due to OH [Cox et al., 1995; Miller et al., 1998]. The mean surface HCFC-22 concentration is still rising, from 110 ppt in 1995 to $188-192$ ppt in 2008 [Montzka et al., 2011; Saikawa et al., 2012].

\footnotetext{
${ }^{1}$ Laboratoire des Sciences du Climat et de l'Environnement, Institut Pierre-Simon Laplace, CEA/CNRS/UVSQ, Gif-sur-Yvette, France.

${ }^{2}$ School of Earth and Atmospheric Sciences, Georgia Institute of Technology, Atlanta, Georgia, USA.

${ }^{3}$ National Institute for Environmental Studies, Tsukuba, Japan.

${ }^{4}$ ENEA-Italian National Agency for New Technologies, Energy and Sustainable Economic Development, Rome, Italy.
}

Corresponding author: A. Fortems-Cheiney, Laboratoire des Sciences du Climat et de l'Environnement, Institut Pierre-Simon Laplace, CEA/ CNRS/UVSQ, CEA Orme des Merisiers, FR-91191 Gif-sur-Yvette, France. (audrey.fortems@1sce.ipsl.fr)

(C)2013. American Geophysical Union. All Rights Reserved. 2169-897X/13/10.1002/jgrd.50544
[3] HCFC-22 is an important topic for research in atmospheric sciences both as a greenhouse gas and as an ozone-depleting substance. Its global warming potential reaches 1790 over the 100 yr time horizon, according to the World Meteorological Organization. Since 1996, HCFC-22 has been an interim replacement gas for more potent ozone-depleting substances such as chlorofluorocarbons (CFCs). However, it is itself ranked among the Class-1 controlled substances in Annex $\mathrm{C}$ of the Montreal Protocol on Substances that Deplete the Ozone Layer (hereafter referred to as the Montreal Protocol). In this context, aggregated global production and sales of individual HCFCs (including HCFC-22) are listed by the Alternative Fluorocarbons Environmental Acceptability Study (AFEAS) until 2007. Parties to the Montreal Protocol are also required to submit their annual consumption (referred to as production plus imports minus exports) to the United Nations Environment Programme (UNEP). At their 19th meeting in 2007, parties to the Montreal Protocol agreed on an accelerated phase-out of HCFCs [U.N. Environment Programme, 2007], covering only the dispersive application (not the feedstock in fluoropolymer manufacture). In developed countries, the phase-out shall have been largely completed by 2020 when the consumption shall have been reduced by $99.5 \%$ compared with the $\mathrm{CFC}$ and $\mathrm{HCFC}$ consumption in $1989(-35 \%$ in $2004 ;-75 \%$ in 2010 ; $-90 \%$ in 2015). In developing countries (parties operating under Article 5 of the Montreal Protocol), consumption of HCFC-22 for emissive uses shall be largely phased out by 2030 . In 2030 , the consumption shall be reduced by $97.5 \%$ compared with the average level in 2009 and 2010 (freeze in $2013 ;-10 \%$ in $2015 ;-35 \%$ in $2020 ;-67.5 \%$ in 2025$)$. 
Table 1. HCFC-22 Measurements Site Information

\begin{tabular}{|c|c|c|c|c|c|c|c|}
\hline Station & Code & Latitude & Longitude & Altitude (m.a.s.l) & Network & Type & Data Period Used \\
\hline Alert, Canada & ALT & 82.50 & -62.30 & 210 & NOAA & flask & $12 / 1994$ to $03 / 2011$ \\
\hline Pt. Barrow, AK, USA & BRW & 71.30 & -156.60 & 11 & NOAA & flask & $12 / 1994$ to $03 / 2011$ \\
\hline Cape Grim, Tasmania & CGO & -40.68 & 144.68 & 104 & AGAGE & continuous & $01 / 1998$ to $03 / 2011$ \\
\hline Cape Grim, Tasmania & CGO & -40.68 & 144.68 & 21 & NOAA & flask & $12 / 1994$ to $03 / 2011$ \\
\hline Cape Ochi-ishi, Japan & $\mathrm{COI}$ & 43.15 & 145.50 & 96 & NIES & continuous & $08 / 2006$ to $12 / 2010$ \\
\hline Hateruma, Japan & HAT & 24.05 & 123.80 & 46.5 & NIES & continuous & $05 / 2004$ to $12 / 2010$ \\
\hline Harvard Forest, USA & HFM & 42.90 & -72.30 & 340 & NOAA & flask & $11 / 1995$ to $03 / 2011$ \\
\hline Jungfraujoch, Switzerland & JFJ & 46.54 & 7.98 & 3580 & AGAGE & continuous & $01 / 2000$ to $03 / 2011$ \\
\hline Cape Kumakahi, HI, USA & KUM & 19.52 & -154.82 & 3 & NOAA & flask & $11 / 1995$ to $03 / 2011$ \\
\hline Park Falls, WI, USA & LEF & 45.92 & -90.27 & 868 & NOAA & flask & $10 / 1996$ to $03 / 2011$ \\
\hline Lampedusa, Italy & LMP & 35.52 & 12.63 & 45 & ENEA & flask & $12 / 2003$ to $12 / 2008$ \\
\hline Mace Head, Ireland & MHD & 53.33 & -9.90 & 25 & AGAGE & continuous & $12 / 1994$ to $03 / 2011$ \\
\hline Mace Head, Ireland & MHD & 53.33 & -9.90 & 8 & NOAA & flask & $10 / 1998$ to $03 / 2011$ \\
\hline Mauna Loa, USA & MLO & 19.54 & -155.58 & 3397 & NOAA & flask & $12 / 1994$ to $03 / 2011$ \\
\hline Niwot Ridge, CO, USA & NWR & 40.03 & -105.54 & 3021 & NOAA & flask & $12 / 1994$ to $03 / 2011$ \\
\hline Palmer Station, Antarctica & PSA & -64.92 & -64.00 & 10 & NOAA & flask & $12 / 1997$ to $03 / 2011$ \\
\hline Ragged Point, Barbados & $\mathrm{RPB}$ & 13.17 & -59.43 & 42 & AGAGE & continuous & $05 / 2005$ to $03 / 2011$ \\
\hline Cape Matatula, Samoa & SMO & -14.24 & -170.57 & 77 & AGAGE & continuous & $05 / 2006$ to $03 / 2011$ \\
\hline Cape Matatula, Samoa & $\mathrm{SMO}$ & -14.24 & -170.57 & 42 & NOAA & flask & $12 / 1994$ to $03 / 2011$ \\
\hline South Pole, USA & SPO & -89.98 & -24.80 & 2810 & NOAA & flask & $12 / 1994$ to $03 / 2011$ \\
\hline Summit, Greenland & SUM & 72.58 & -38.48 & 3238 & NOAA & flask & $06 / 2004$ to $03 / 2011$ \\
\hline Tierra del Fuego, Argentina & TDF & -54.87 & -68.48 & 20 & NOAA & flask & $05 / 2004$ to $05 / 2010$ \\
\hline Trinidad Head, CA, USA & THD & 41.05 & -124.15 & 120 & NOAA & flask & $03 / 2002$ to $03 / 2011$ \\
\hline Trinidad Head, CA, USA & THD & 41.05 & -124.15 & 140 & AGAGE & continuous & $03 / 2005$ to $03 / 2011$ \\
\hline Ny-Alesund, Norway & ZEP & 78.90 & 11.88 & 474 & AGAGE & continuous & $01 / 2001$ to $03 / 2011$ \\
\hline
\end{tabular}

[4] However, emissions are more relevant than consumption data to estimate the HCFC-22 loading to the atmosphere, and there is a growing interest in better estimating global and regional emissions of this species. McCulloch et al. [2003] estimated global annual emissions for the years 1943-2000, a study that has been updated and lengthened up to 2015 by McCulloch [2005], based on the UNEP statistics. McCulloch et al. [2003] also built gridded emission estimates for the specific year 1990. Stohl et al. [2009] created and inferred their own gridded HCFC-22 emissions, using an inverse procedure and a Lagrangian transport model. Stohl et al. [2010] inferred HCFC-22 emissions from four East Asian countries and the Taiwan region. Saikawa et al. [2012] also built gridded prior emissions for the years 1995-2009 and optimized the HCFC-22 annual emissions at global (for years 1995-2009) and regional (for years 20052009) scales. These authors found that global HCFC-22 emissions have a positive trend from 1995 to 2009 [Saikawa et al., 2012], with an important contribution of China [Stohl et al., 2009, 2010; Saikawa et al., 2012]. Nevertheless, they estimated regional fluxes for relatively large predefined regions, inducing aggregation errors [Kaminski et al., 2001], and for relatively short periods (years 2005-2009 for Saikawa et al. [2012], years 2005-2006 for Stohl et al. [2009], and year 2008 for Stohl et al. [2010]).

[5] For the present study, we develop an atmospheric inversion system with high spatial and temporal resolutions: the quantification of the HCFC-22 fluxes is attempted at the grid-cell resolution of our global chemistry-transport model $\left(3.75^{\circ} \times 2.5^{\circ}\right)$ and at an 8 day resolution. The HCFC22 fluxes are inferred over the long period of 16 years (1995-2010), with a simultaneous optimization of $\mathrm{OH}$ concentrations for four latitudinal bands. The components of the inversion system are described in section 2. Section 3 provides the global and regional trend and variability of HCFC-22 emissions over the period 1995-2010.

\section{Methodology}

[6] Our approach consists in optimizing the sources and sinks of a trace gas within a Bayesian framework. It requires atmospheric measurements $\mathbf{y}$, prior estimates of the source and sink space-time distributions $\mathbf{x}_{\mathbf{b}}$, and a chemistrytransport model $H$, given their respective uncertainties represented by their error covariance matrix $\mathbf{R}$ and $\mathbf{B}$. The optimal solution (in a statistical sense), which is called posterior in the following, is found by the iterative minimization of the Bayesian cost function $J$ defined as follows:

$$
J(\mathbf{x})=\left(\mathbf{x}-\mathbf{x}_{b}\right)^{\mathrm{T}} \mathbf{B}^{-1}\left(\mathbf{x}-\mathbf{x}_{b}\right)+(H(\mathbf{x})-\mathbf{y})^{\mathrm{T}} \mathbf{R}^{-1}(H(\mathbf{x})-\mathbf{y})
$$

where $\mathbf{x}$ is the state vector that contains the variables to be optimized by the inversion:

[7] 1. HCFC-22 surface emissions at an 8 day and at a $3.75^{\circ} \times 2.5^{\circ}$ (longitude, latitude) resolution.

[8] 2. HCFC-22 column initial conditions at a $3.75^{\circ} \times$ $2.5^{\circ}$ resolution.

[9] 3. Four factors to scale the $\mathrm{OH}$ atmospheric concentrations at an 8 day resolution, for four latitude bands $\left(90^{\circ} \mathrm{S}-30^{\circ} \mathrm{S}, 30^{\circ} \mathrm{S}-0^{\circ} \mathrm{S}, 0^{\circ} \mathrm{S}-30^{\circ} \mathrm{N}, 30^{\circ} \mathrm{N}-90^{\circ} \mathrm{N}\right)$.

[10] The operator $H$ is the global 3-D Chemistry Transport Model (CTM) LMDz-SACS that couples an offline version of the atmospheric general circulation model LMDz [Hourdin et al., 2006] with the atmospheric chemistry module SACS (Simplified Atmospheric Chemistry System) [Pison et al., 2009]. For this study, SACS has been adapted to represent the interaction between $\mathrm{OH}$ and HCFC-22. The most important sink for HCFC-22 in the troposphere is its reaction with $\mathrm{OH}: \mathrm{CHClF}_{2}+$ $\mathrm{OH} \cdot \longrightarrow \mathrm{CF}_{2} \mathrm{Cl} \cdot+\mathrm{H}_{2} \mathrm{O}$. SACS uses the reaction rate $\mathrm{k}=1.05 \times 10^{12} \exp ^{\left(\frac{1600}{T}\right)} \mathrm{cm}^{3}$ molecule $^{-1} \mathrm{~s}^{-1}$, as recommended by Sander et al. [2011]. Its other sinks are neglected in SACS. The $\mathrm{OH}$ prior distribution is obtained from a previous simulation of the full atmospheric chemistry 


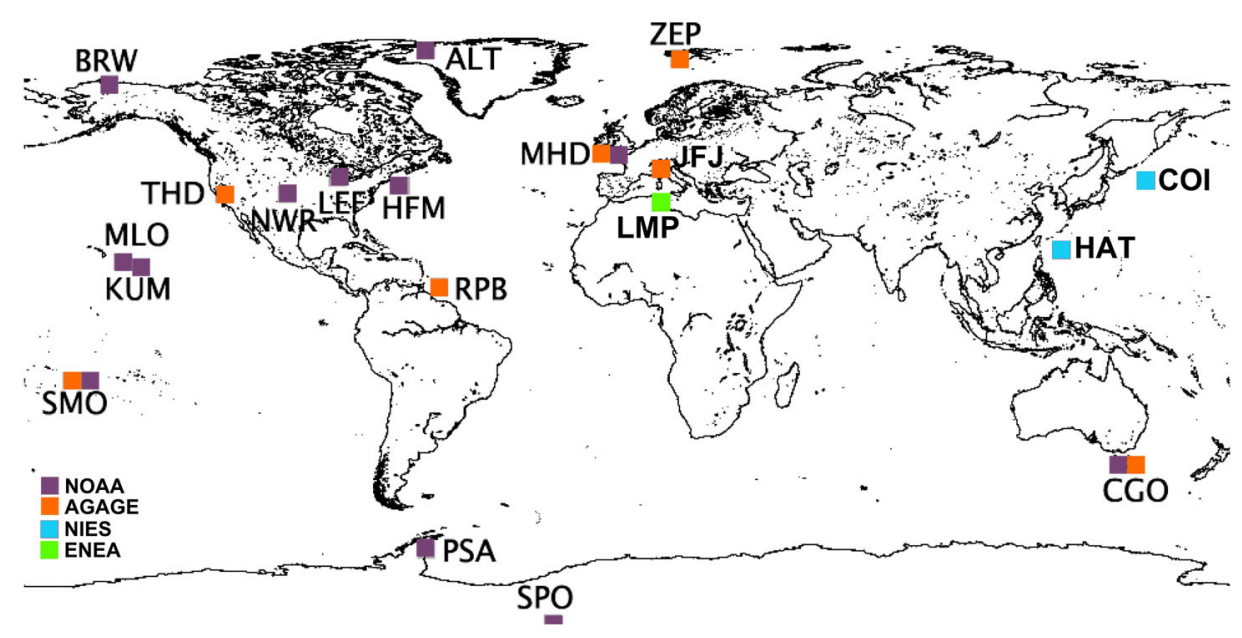

Figure 1. Locations of the stations measuring HCFC-22 dry air mole fraction.

model LMDz-INCA (Intéractions Chimie et Aérosols [Hauglustaine et al., 2004]).

[11] The observations in $\mathbf{y}$ gather HCFC-22 dry air mole fractions measured at 29 stations (Table 1) for the 1995-2010 period, available on the World Data Centre for Greenhouse Gases site (http://ds.data.jma.go.jp/gmd/ wdcgg/, accessed 15 November 2012). We use instantaneous values, named "event" in the database, from flask (from the National Oceanic and Atmospheric Administration, Earth System Research Laboratory (NOAA/ESRL) [Montzka et al., 1993] and from the Italian National Agency for New Technologies, Energy and Sustainable Economic Development (ENEA) [Artuso et al., 2010] networks) and from continuous measurements (from the Advanced Global Atmospheric Gases Experiment (AGAGE) [O'Doherty et al., 2004; Saikawa et al., 2012] and from the National Institute for Environmental Studies (NIES) [Yokouchi et al., 2006] networks). The monitoring stations are mainly located in the Northern Hemisphere and particularly around North America (Figure 1). The yearly numbers of measurements used in the inversion are displayed in Figure 2. The number of measurements remains small until 1998 (148 in 1995, 181 in 1996, 210 in 1997, and 1351 in 1998), but it has risen continuously since 1998: from a few thousands between 1998 and 2003 to more than 25,000 in 2007 onwards.

[12] The diagonal $\mathbf{R}$ matrix representing observation errors is filled with variances which combine representation errors (e.g., the mismatch between the observation and model resolutions), errors of the observation operator (including transport and chemical-scheme errors in LMDZSACS), and measurement errors including instrumental precision for HCFC-22 measurements of approximately 0.4 $1 \%$ and the errors involved in the calibration scale of approximately 1\% [Saikawa et al., 2012]. Differences between networks (calibrations uncertainties, intercalibration factors) are small considering other causes of uncertainties such as representation or model errors. The errors on the observation operator and the representation error are difficult to estimate precisely. The synoptic variability reported in the NOAA and ENEA files is taken as a proxy for observation uncertainty, which includes transport model error. Such information is not given in the AGAGE and NIES files, and a value of $3 \mathrm{ppt}$ has been assigned to the observation error standard deviation.

[13] In the absence of established gridded inventories of the HCFC-22 emissions, we follow the methodology of Stohl et al. [2009] to build our gridded prior information in $\mathbf{x}_{\mathbf{b}}$ : we combine (1) the global annual emission estimates of McCulloch [2005], including their forecast for years 2002 to 2010 ; (2) the country totals for the annual consumption of HCFCs (i.e., not only HCFC-22) from 1995 to 2010, available from the United Nations Environment Programme (UNEP 2011, Data Access Centre, available at: http://ozone. unep.org/new_site/en/ozone_data_tools_access.php) and (3) a population distribution over the globe for year 1995, available from the Distributed Active Archive Center for Biogeochemical Dynamics (ORNL DAAC, http://daac.ornl. gov/projects.shtml). Given the $3.75^{\circ} \times 2.5^{\circ}$ resolution of our grid, we exploit the UNEP country totals after aggregation at subcontinental scales (14 continental regions). The relative contribution of each region to the global consump-

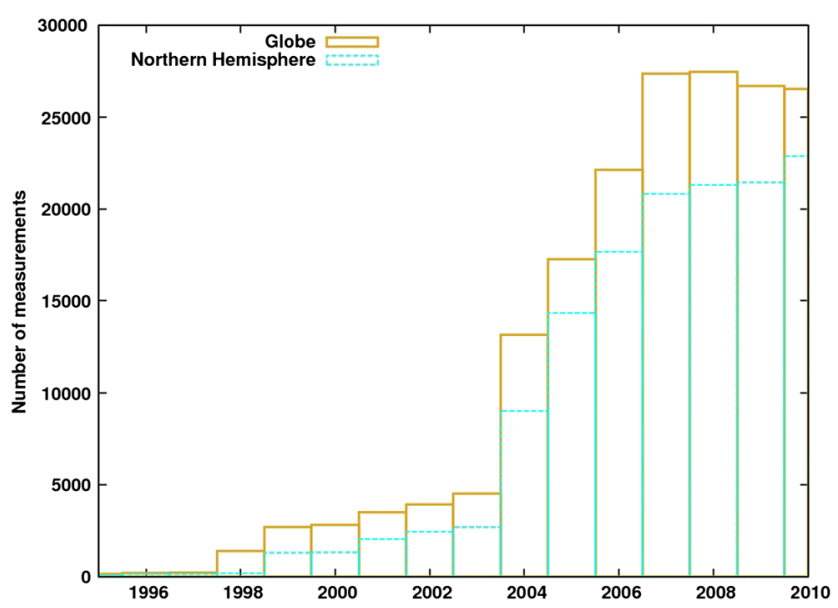

Figure 2. Number of measurements per year, for the globe (in yellow) and for the Northern Hemisphere (in blue), from 1995 to 2010. 

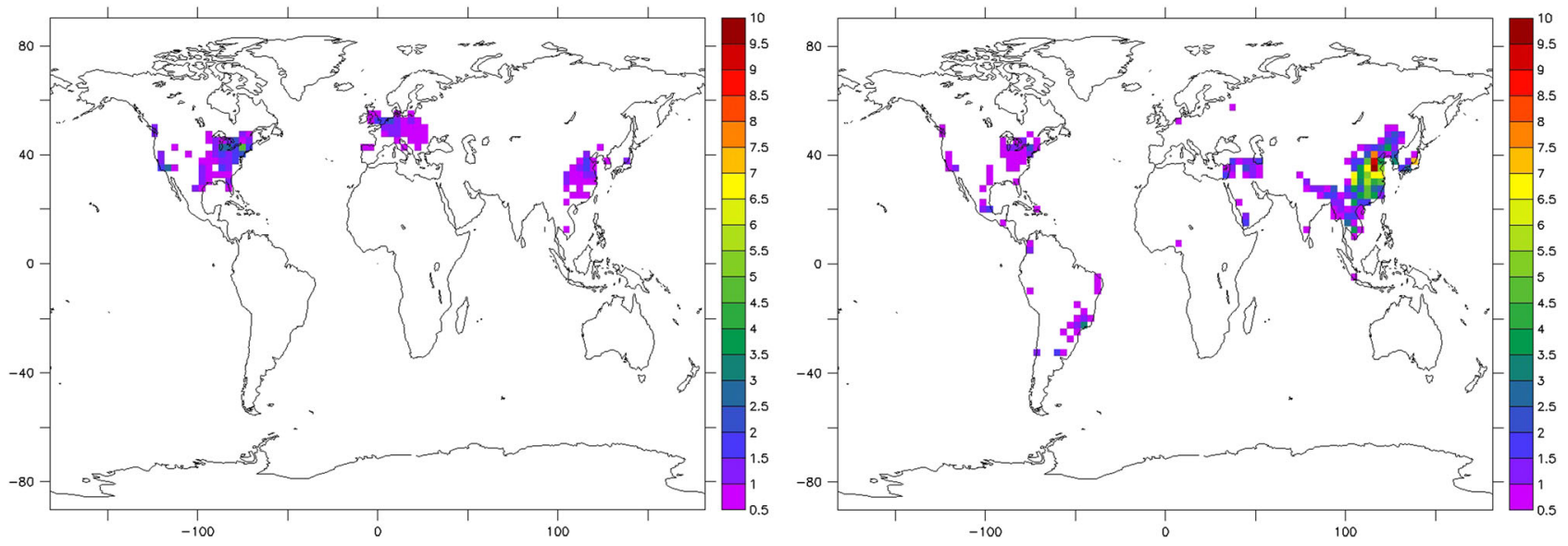

Figure 3. Prior HCFC-22 emissions for (left) 1995 and (right) 2010 prepared for this study, at the grid resolution, in $\mathrm{Gg} / \mathrm{yr}$.

tion is calculated and is taken as the relative contribution of each region to the global emissions. The regional emissions are then distributed proportionally to the population, at the $3.75^{\circ} \times 2.5^{\circ}$ pixel resolution. They are left constant within each year. For some countries, the HCFC consumption in 2010 is missing in the UNEP inventory (UNEP, 2011). Therefore, our prior emissions for 2010 are assumed to be equal to our prior emissions for 2009. Figure 3 shows the resulting gridded maps of the prior HCFC-22 emissions and displays the evolution of the HCFC-22 emissions in the world from 1995 to 2010, after the Montreal Protocol: emissions increase in developing countries and decrease in developed countries.

[14] We represent the uncertainty of this prior inventory of our prior $\mathrm{OH}$ field and of our initial conditions in the covariance matrix $\mathbf{B}$ (see equation (1)). The grid point standard deviations for the HCFC-22 emissions (i.e., the diagonal terms of $\mathbf{B}$ ) are set at a relatively large value, $60 \%$, because of the large and uncertain interannual variability of the regional HCFC-22 emissions in recent years. For the initial conditions, errors are set to $10 \%$ for HCFC-22. The errors assigned to the scale factor of $\mathrm{OH}$ are set at $10 \%$,
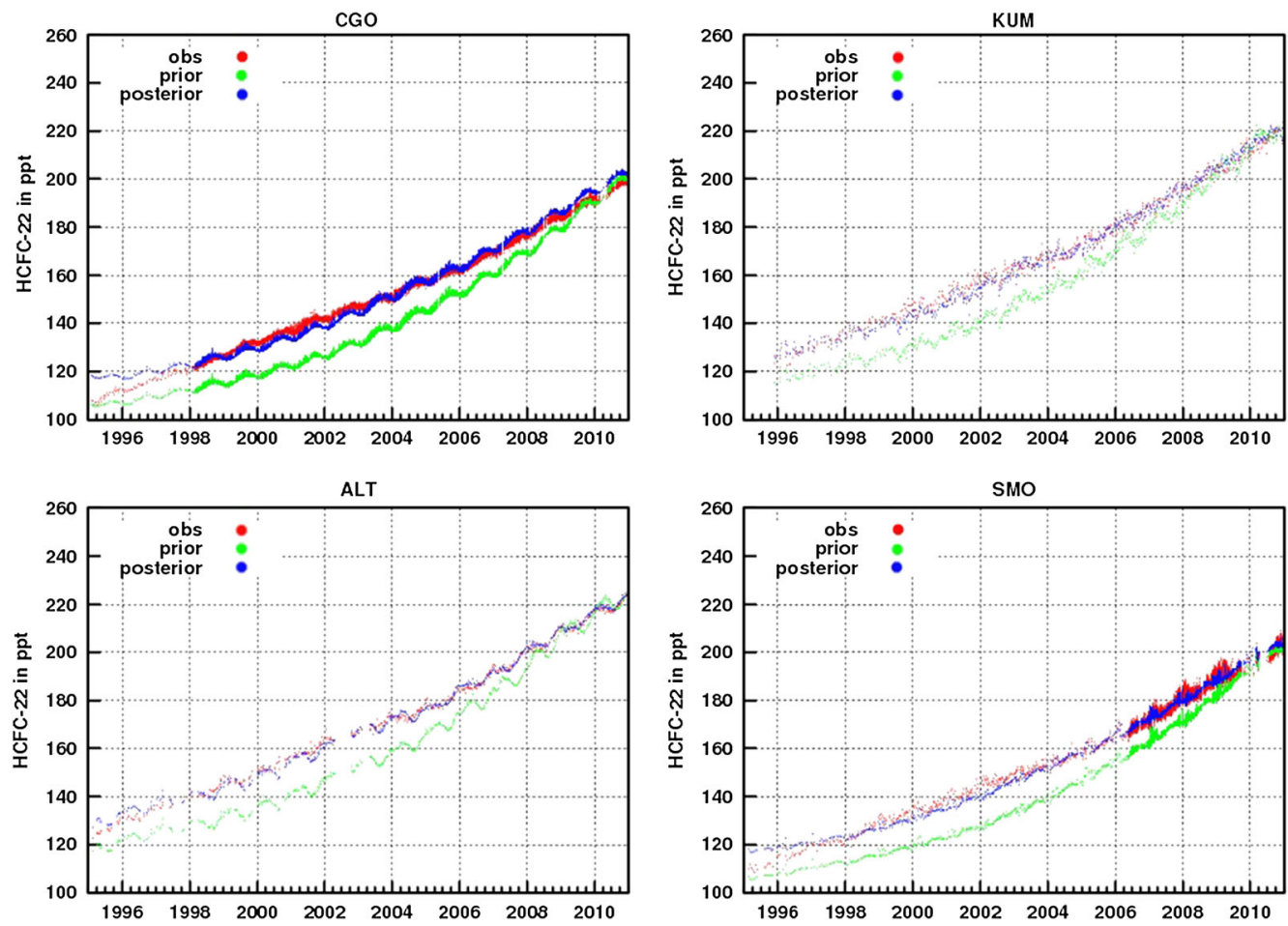

Figure 4. Simulated prior (green) and posterior (blue) compared to the observed HCFC-22 concentrations (red), from 1995 to 2010 at stations Alert (ALT), Cape Kumukahi (KUM), American Samoa (SMO), and Cape Grim (CGO). See Figure 1 for the station locations. 
Table 2. Global HCFC-22 Emissions and Their Uncertainties for Years 1995 to 2010 Before the Inversion and After the Inversion, in $\mathrm{Gg} / \mathrm{yr}$

\begin{tabular}{cccccc}
\hline & Prior & Posterior & & Prior & Posterior \\
\hline 1995 & $173 \pm 14$ & $182 \pm 11$ & 2003 & $278 \pm 19$ & $279 \pm 8$ \\
1996 & $187 \pm 14$ & $198 \pm 11$ & 2004 & $302 \pm 19$ & $289 \pm 8$ \\
1997 & $187 \pm 14$ & $199 \pm 11$ & 2005 & $324 \pm 26$ & $320 \pm 9$ \\
1998 & $195 \pm 14$ & $212 \pm 11$ & 2006 & $350 \pm 26$ & $338 \pm 9$ \\
1999 & $210 \pm 14$ & $227 \pm 11$ & 2007 & $369 \pm 26$ & $371 \pm 9$ \\
2000 & $229 \pm 19$ & $256 \pm 8$ & 2008 & $415 \pm 26$ & $375 \pm 9$ \\
2001 & $241 \pm 19$ & $266 \pm 8$ & 2009 & $416 \pm 26$ & $410 \pm 9$ \\
2002 & $264 \pm 19$ & $270 \pm 8$ & 2010 & $416 \pm 26$ & $386 \pm 9$ \\
\hline
\end{tabular}

which is consistent with the differences between estimates of the $\mathrm{OH}$ concentrations from several studies [Prinn et al., 2001; Krol and Lelieveld, 2003; Bousquet et al., 2005]. Assuming that the approach used to build the prior inventory leads to errors that are coherent at large space-time scales, spatial correlations are represented by an e-folding length of $500 \mathrm{~km}$ over land (1000 km over sea), without any correlation between land and ocean, and we prescribe a temporal correlation e-folding length of 8 weeks. These prior error statistics lead the HCFC-22 prior error emissions (displayed in Figure 9a) as an example for the year 2007 and to annual HCFC-22 budgets of $173 \pm 14 \mathrm{Gg} / \mathrm{yr}$ in 1995 and of $416 \pm 26 \mathrm{Gg} / \mathrm{yr}$ in 2010 . Here and in the following, the numbers behind the plus-minus signs refer to one-sigma standard deviations.

[15] The cost function $J$ and the norm of its gradient are minimized with the quasi-Newton minimization algorithm M1QN3 [Gilbert and Lemaréchal, 1989]. After 17 iterations corresponding to 4 weeks of sustained parallel computing (on eight Intel Xeon 64 bit CPUs), the norm of the gradient is reduced by $99.9 \%$. The uncertainty on the posterior emissions is calculated with the Monte Carlo approach of Chevallier et al. [2007]. As a trade-off between computing resources and exhaustivity, we only estimate the posterior one-sigma uncertainty for the years 1997, 2002, and 2007. In the following, these values are used to characterize the 5 year periods 1995-1999, 2000-2004, and 2005-2010, respectively. Conservatively, we also applied these uncertainties to multiyear averages, even though these values are probably overestimated.

\section{Results}

\subsection{Prior and Posterior Fit at Stations}

[16] Figure 4 shows the simulated prior (in green), the simulated posterior (in blue), and the measured (in red) HCFC-22 concentrations, from 1995 to 2010, at stations Alert (ALT), Cape Kumukahi (KUM), American Samoa (SMO), and Cape Grim (CGO), representative of the four latitude bands chosen for the $\mathrm{OH}$ constraint. Observed concentrations have increased continuously since 1995, from $120 \mathrm{ppt}$ in 1995 to more than $220 \mathrm{ppt}$ in 2010 in the Northern Hemisphere (from $105 \mathrm{ppt}$ in 1995 to $200 \mathrm{ppt}$ in 2010 in the Southern Hemisphere). The mean observed growth rate of about $+5.5 \mathrm{ppt} / \mathrm{yr}$ for the $1995-2005$ period (similar to the rate of $6 \mathrm{ppt} / \mathrm{yr}$ measured by O'Doherty et al. [2004] at stations MHD and CGO) has slightly increased in both hemispheres after 2006, with about $+7.9 \mathrm{ppt} / \mathrm{yr}$ for the 2006 2010 period (similar to the averaged annual growth rate of $8.0 \pm 0.5 \mathrm{ppt} / \mathrm{yr}$ deduced by Montzka et al. [2011] during 2007-2008). This also accords with the increasing growth rate beginning since 2006 seen by Saikawa et al. [2012].

[17] Compared to the observed concentrations, an underestimation by about 5\% is seen during the period 1995 2005 in the prior-modeled concentrations (growth rate of about $+4.3 \mathrm{ppt} / \mathrm{yr}$ ). Slight overestimations are seen after 2008 (growth rate of about $9 \mathrm{ppt} / \mathrm{yr}$ ). After optimization, the model does not succeed in capturing the magnitude of HCFC-22 observations for the stations CGO and SMO from 1995 to 1998 . This mainly results from very low number of HCFC-22 observations in the Southern Hemisphere

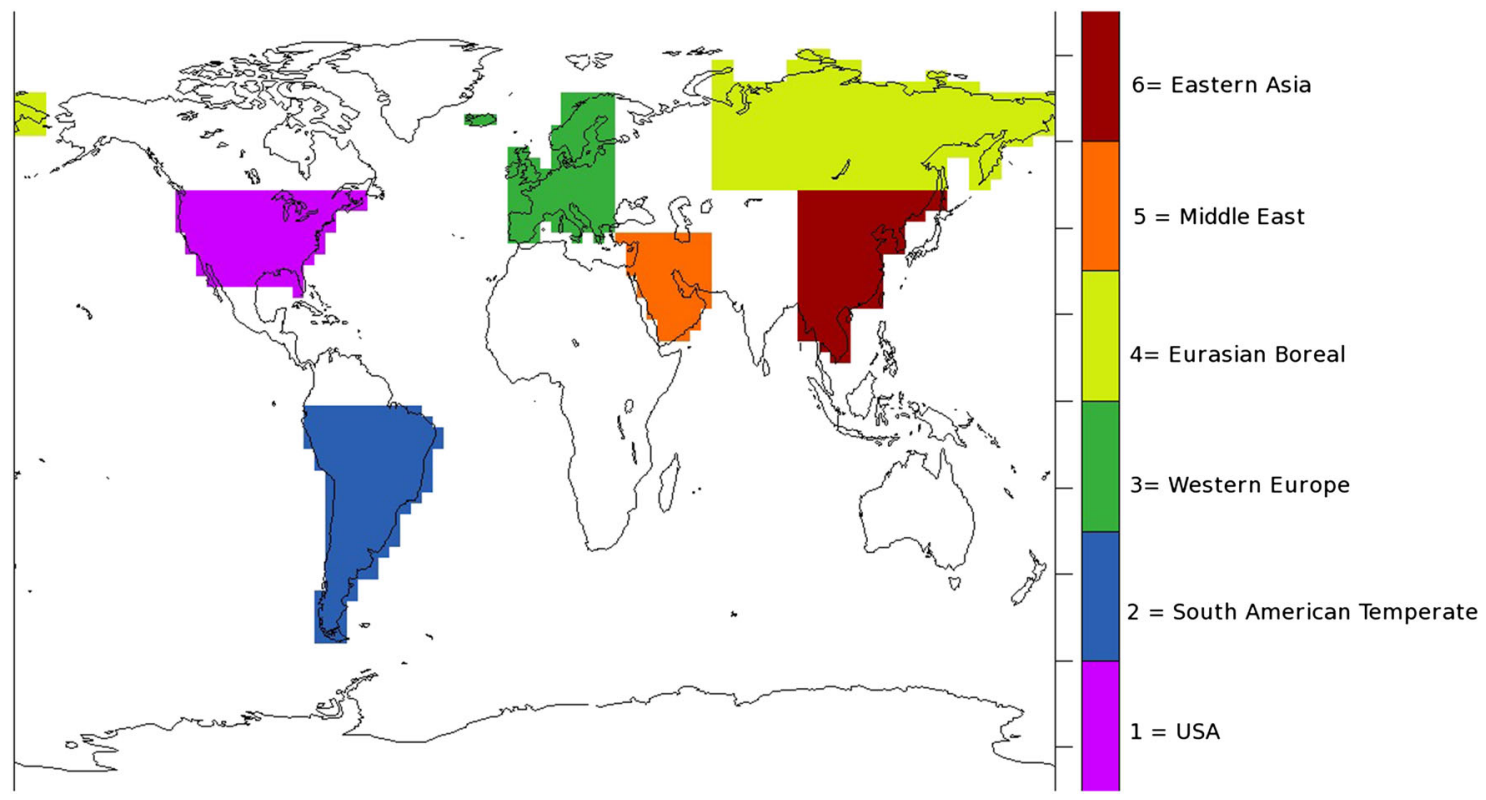

Figure 5. Partition into six regions. 

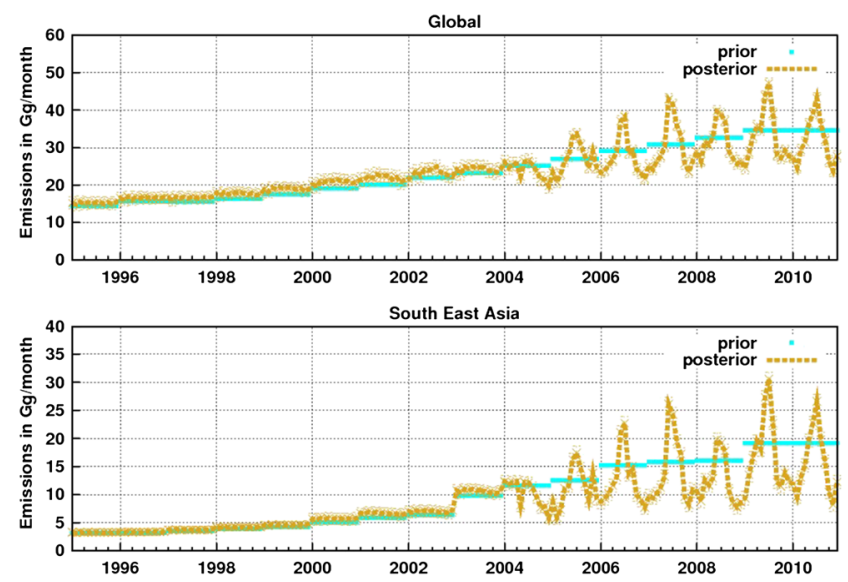

Figure 6. Monthly prior (in blue) and posterior (in yellow) HCFC-22 emissions for the globe (top) and for Eastern Asia (bottom) from 1995 to 2010. Error bars denote the posterior one-sigma uncertainty in the monthly emissions estimates.

during these years. Nevertheless, the posterior simulation is in excellent agreement with the HCFC-22 observations from 1998 to 2010 .

\subsection{Global Budget of HCFC-22 Emissions}

[18] Figure 6 (top) displays the global monthly prior and posterior HCFC-22 emissions from 1995 to 2010. Prior and posterior emissions consistently represent a rise of the emissions from 1995 to 2010 (also seen in Table 2). The global posterior emissions are reduced by a maximum of $10 \%$ compared to prior values, indicating the good quality of the forecast made by McCulloch [2005] used here as prior.

[19] Posterior HCFC-22 emissions range from $182 \pm$ $11 \mathrm{Gg} / \mathrm{yr}$ in 1995 (starting from a prior of $173 \pm 14 \mathrm{Gg} / \mathrm{yr}$, see Table 2) to the maximum of $410 \pm 9 \mathrm{Gg} / \mathrm{yr}$ in 2009 (starting from a prior of $415 \pm 26 \mathrm{Gg} / \mathrm{yr}$ ). Our posterior global budget is in a reasonable agreement with other recent
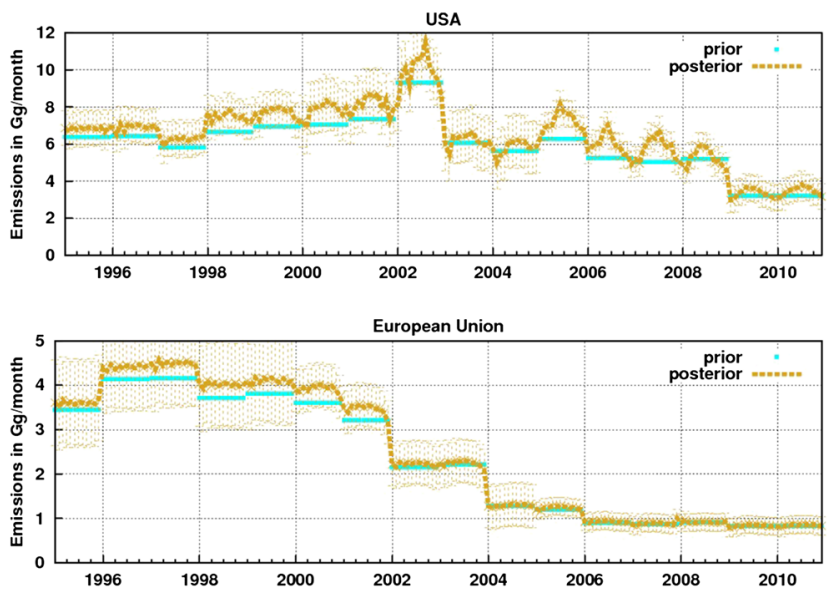

Figure 7. Monthly prior (in blue) and posterior (in yellow) HCFC-22 emissions for the USA (top) and for Western Europe (bottom), from 1995 to 2010. Error bars denote the posterior one-sigma uncertainty in the monthly emissions estimates.
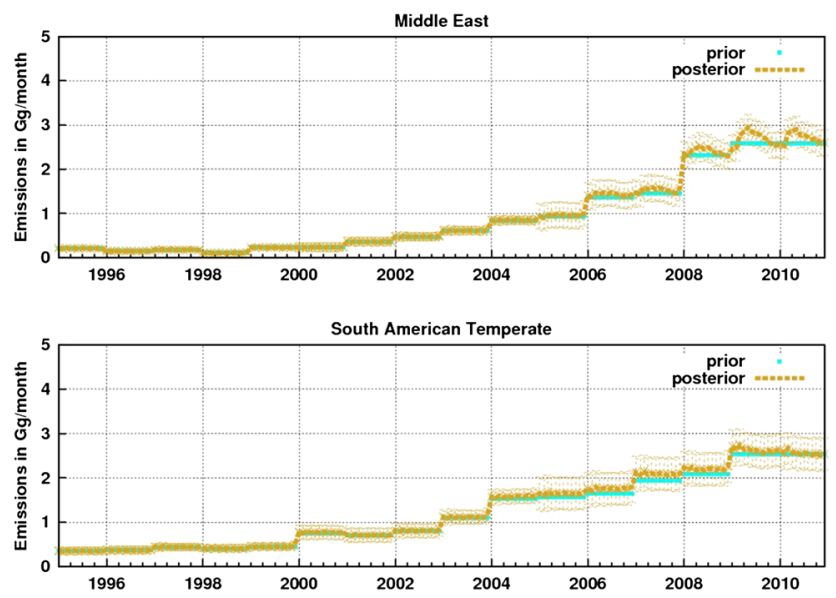

Figure 8. Monthly prior (in blue) and posterior (in yellow) HCFC-22 emissions for the regions Middle East (top) and South American Temperate (bottom), from 1995 to 2010. Error bars denote the posterior one-sigma uncertainty in the monthly emissions estimates.

studies: over the period 2005-2009, we find a posterior global budget of $363 \pm 9 \mathrm{Gg} / \mathrm{yr}$ (starting from a prior of $382 \pm 26 \mathrm{Gg} / \mathrm{yr}$ ), which is $13 \%$ higher than the optimized magnitudes obtained by Saikawa et al. [2012] with $314.6 \pm$ $79 \mathrm{Gg} / \mathrm{yr}$. Over the period 2005-2006, our posterior budget of $329 \pm 9 \mathrm{Gg} / \mathrm{yr}$ (starting from a prior of $337 \pm 26 \mathrm{Gg} / \mathrm{yr}$ ) is also in a fair agreement with the $333 \mathrm{Gg} / \mathrm{yr}$ of Stohl et al. [2009]. Our posterior budget of $371 \pm 9 \mathrm{Gg} / \mathrm{yr}$ in 2007 (starting from a prior of $369 \pm 26 \mathrm{Gg} / \mathrm{yr}$ ) is only $1 \%$ higher than the optimized magnitudes obtained by Vollmer et al. [2009] (365 Gg/yr).

\subsection{Regional Budget}

[20] We investigate the regional variations of HCFC-22 emissions by aggregating the grid point estimates over the

Table 3. Regional HCFC-22 Emissions and Their Uncertainties for the Years 1997, 2002, and 2007, in $\mathrm{Gg} / \mathrm{yr}^{\mathrm{a}}$

\begin{tabular}{lcccc}
\hline & & Prior & Posterior & Error Reduction \\
\hline USA & 1997 & $70 \pm 9$ & $75 \pm 8$ & 10 \\
& 2002 & $112 \pm 12$ & $110 \pm 8$ & 37 \\
Western Europe & 2007 & $60 \pm 6$ & $71 \pm 6$ & 4 \\
& 1997 & $50 \pm 6$ & $55 \pm 6$ & 3 \\
Eurasian Boreal & 2002 & $26 \pm 3$ & $26 \pm 3$ & 5 \\
& 2007 & $10 \pm 1$ & $11 \pm 1$ & 2 \\
Eastern Asia & 2097 & $0.5 \pm 0.1$ & $0.5 \pm 0.1$ & - \\
& 2007 & $10 \pm 1$ & $9 \pm 1$ & 2 \\
& 1997 & $42 \pm 4$ & $46 \pm 4$ & 11 \\
South Am Temp & 2002 & $77 \pm 8$ & $84 \pm 6$ & 24 \\
& 2007 & $190 \pm 20$ & $176 \pm 5$ & 75 \\
& 2097 & $5 \pm 0.5$ & $5 \pm 0.5$ & - \\
& 2007 & $10 \pm 1$ & $10 \pm 1$ & 1 \\
& 1997 & $23 \pm 0.3$ & $2 \pm \pm 0.3$ & 6 \\
Middle East & 2002 & $6 \pm 1$ & $6 \pm 1$ & - \\
& 2007 & $17 \pm 2$ & $19 \pm 2$ & 3 \\
\hline
\end{tabular}

${ }^{\mathrm{a}}$ The regional error reduction is indicated in $\%$. 

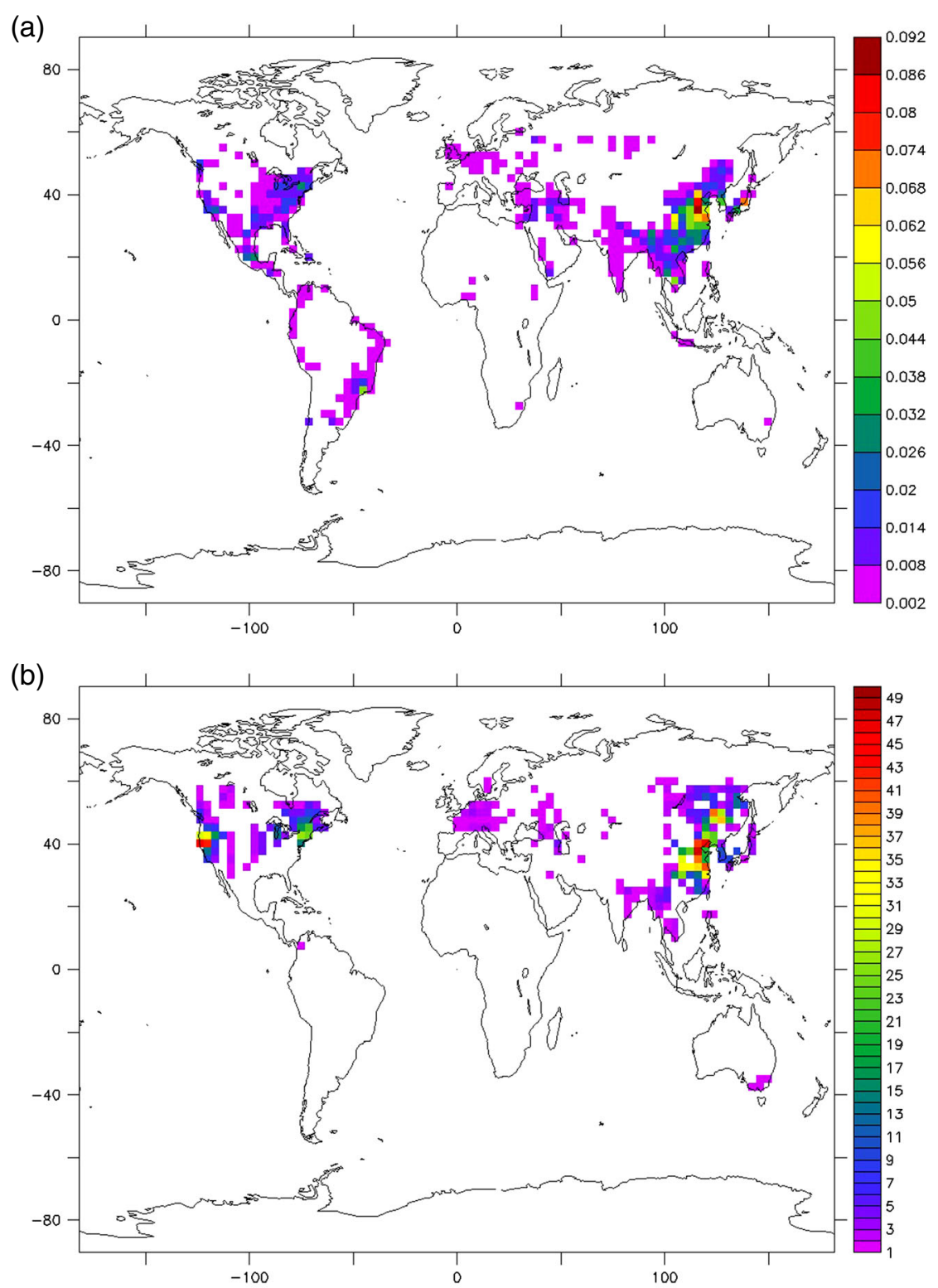

Figure 9. (a) Prior errors on HCFC-22 emissions at the grid-cell resolution for year 2007, in Gg/yr. (b) Uncertainty reduction obtained by the inversion at the grid-cell resolution for the year 2007 , in $\%$.

six main source regions of Figure 5 (three for developed countries: USA, Western Europe, and Russia; three for developing countries: Eastern Asia, Middle East, and South American Temperate). Our 2005-2006 average estimate for the US emissions $(80 \pm 7 \mathrm{Gg} / \mathrm{yr}$, starting from a prior of $69 \pm 8 \mathrm{Gg} / \mathrm{yr}$ ) is, for example, in excellent agreement with the estimates of Stohl et al. [2009] and Saikawa et al. [2012], with $80 \mathrm{Gg}$ and $77 \pm 20 \mathrm{Gg} / \mathrm{yr}$, respectively. We find a significant increase in HCFC-22 emissions from 1995 to 2010 in South American Temperate, Middle East, and in Eastern Asia, particularly in China. The large increase of emissions in the developing regions is not surprising considering the rise in HCFC-22 consumption for this period (UNEP, 2011). These three regions contributed $70 \%$ of the global emissions in 2010. Eastern Asia itself contributes $45 \%$ of these global emissions. The importance of Eastern Asia, and particularly of China, as a HCFC-22 source has been highlighted by Yokouchi et al. [2006], Vollmer et al. [2009], Stohl et al. [2009], and Saikawa et al. [2012]. Our posterior Chinese emissions $(128 \pm 18 \mathrm{Gg} / \mathrm{yr})$ are $22 \%$ lower than the $165 \mathrm{Gg} / \mathrm{yr}$ of Vollmer et al. [2009] in 2007 (starting from a prior of $149 \pm 24 \mathrm{Gg} / \mathrm{yr}$ ). On the contrary, for the year 2008 , our posterior Chinese emissions of $111 \pm 18 \mathrm{Gg} / \mathrm{yr}$ (starting from a prior of $152 \pm 24 \mathrm{Gg} / \mathrm{yr}$ ) are $69 \%$ higher than the estimates of Stohl et al. [2010] (65 Gg/yr \pm 7$)$.

\subsection{Seasonality}

[21] The 8 day resolution of the inversion allows creating seasonal variations in the global posterior emissions (compared to the prior annual estimates, Figure 6, top). A seasonal cycle is seen after 2004, probably because of the increase of measurements (from about 5000 observations 
(a)

(b)
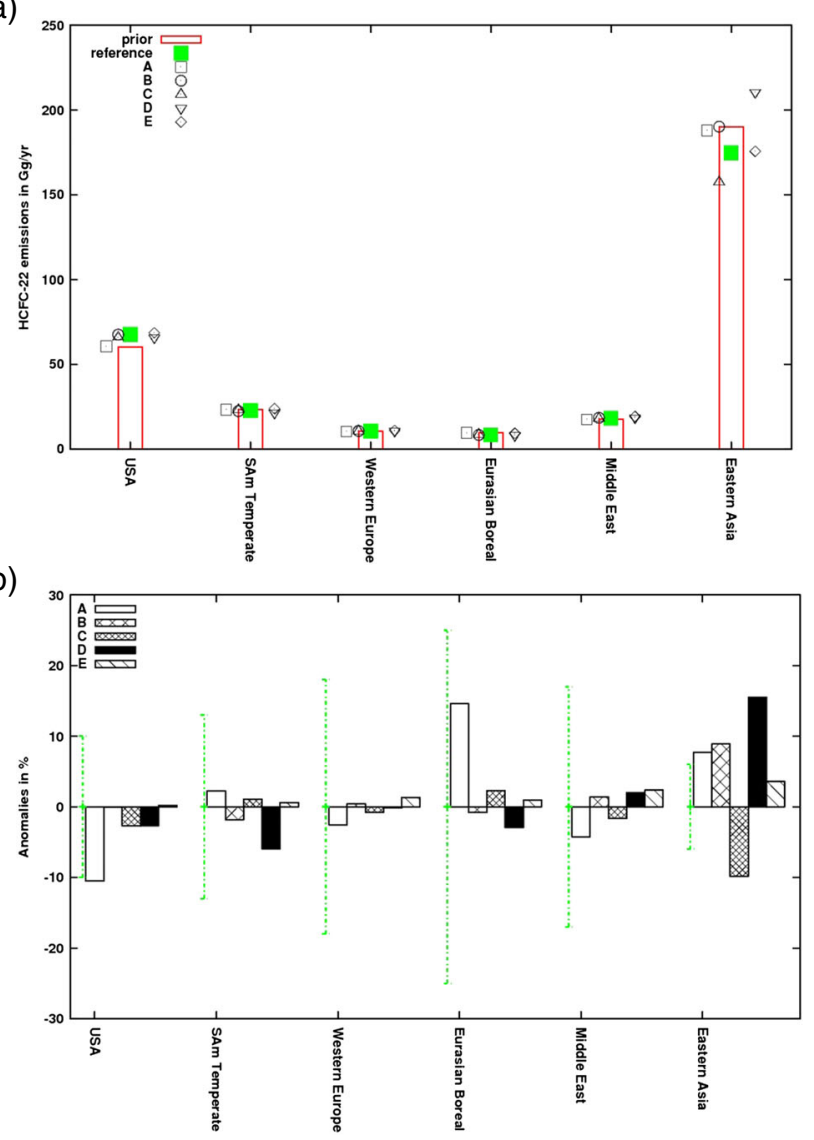

Figure 10. (a) Regional HCFC-22 emissions calculated for year 2007. The red bar represents the prior production and each symbol a posterior production for the reference inversion (in green) and the five sensitivity cases (in black). Case A: stations removed; case B: error on the prior HCFC-22 emissions set to $40 \%$; case C: error on the prior HCFC-22 emissions set to $80 \%$; case D: observations error set to $6 \mathrm{ppb}$; case $\mathrm{E}$ : temporal correlation length set to 4 months. (b) Differences of the posterior HCFC-22 emissions between the sensitivity tests and the reference inversion (in \% relative to the reference). Error bars show the one-sigma uncertainty associated with the posterior reference (calculated using the Monte Carlo approach).

per year in 2003 to more than 15,000 observations per year in 2005, as seen in Figure 2). The posterior sources range from $25 \mathrm{Gg} /$ month in November to $42 \mathrm{Gg} /$ month in July, for example, in 2010. It is interesting to see that few regions drive these seasonal variations: Eastern Asia (Figure 6, bottom, the Asian posterior sources ranging from $10 \mathrm{Gg} / \mathrm{month}$ in winter to $26 \mathrm{Gg} /$ month in boreal summer in 2010) and, to a lesser extent, the USA (Figure 7, top) and the Middle East (Figure 8, bottom).

[22] To our knowledge, such a seasonal cycle has not been referenced yet in the literature. This may be explained by higher needs in refrigeration and air-conditioning during the warmest months of the year, correlated with the maintenance activity of the cooling systems (S. Barrault, personal communication, 2012), during which extra leak of HCFC-22 may occur. Also, these regions are probably responsible for a more extensive use of such systems than other parts of the world. However, artifacts such as misrepresentation of the stratosphere-troposphere exchange in LMDz or a misallocation of the seasonal $\mathrm{OH}$ sink cannot be ruled out, and further work would be needed to better understand these seasonal variations.

\subsection{Performance of the Inversion}

\subsubsection{Uncertainty Reduction}

[23] The uncertainty reductions reached by the inversion for the years 1997, 2002, and 2007 are synthesized in Table 3 for regional and global aggregations. The uncertainty reduction at the grid scale resolution is also shown in Figure $9 \mathrm{~b}$ for year 2007. The uncertainty reduction is defined as $\left(1-\sigma_{a} / \sigma_{b}\right) \times 100$, with $\sigma_{b}$ the prior error standard deviation and $\sigma_{a}$ the theoretical posterior error standard deviation. In 1997, the global error reduction reaches $21 \%$. However, due to fewer observations (210 in that year), the inversion does not reduce the uncertainties on HCFC-22 emissions at regional scale, except over the USA (uncertainty reduction of $10 \%$ ), where most measurement stations are located. Note that these constraints also bring information over the region Eastern Asia (uncertainty reduction of $10 \%$ ), even though there is no station in this region until 2004.

[24] The progressive extension of the surface network (see Figure 2) increases the number of observational constraints in the inversion over time. Combined with the increased emissions in the atmosphere, this leads to larger uncertainty reductions on HCFC-22 emissions since 2002 both at global $(65 \%$ in 2007) and at regional scales (Table 3). Nevertheless, the uncertainty reduction remains small for less constrained and/or emitting regions (i.e., for regions Middle East and South American Temperate, see Figure 9b).

\subsubsection{Sensitivity Tests}

[25] In this section, we discuss the robustness of our system through five sensitivity tests (cases A to E) with respect to different prior settings:

Table 4. HCFC-22 Targets of the Montreal Protocol for Developed Countries ${ }^{\mathrm{a}}$

\begin{tabular}{|c|c|c|c|c|c|c|c|c|}
\hline & \multirow[b]{2}{*}{ Emission Baseline } & \multicolumn{3}{|c|}{2004} & \multicolumn{3}{|c|}{2010} & \multirow{2}{*}{$\frac{2015}{\text { Objective }}$} \\
\hline & & Objective & Prior & Posterior & Objective & Prior & Posterior & \\
\hline USA & 122 & 79 & $57 \pm 15$ & $59 \pm 9$ & 31 & $32 \pm 8$ & $35 \pm 8$ & 12 \\
\hline EU & 47 & 31 & $15 \pm 4$ & $15 \pm 4$ & 12 & $10 \pm 2$ & $10 \pm 2$ & 5 \\
\hline Russia & 48 & 31 & $7 \pm 1$ & $7 \pm 1$ & 12 & $11 \pm 2$ & $9 \pm 2$ & 5 \\
\hline
\end{tabular}

${ }^{\mathrm{a}}$ The emission baseline is calculated with the same methodology as for the prior emissions construction in section 2 but for year 1989 . The 2004 ( $\left.-35 \%\right)$, $2010(-75 \%)$, and $2015(-90 \%)$ objectives compared to the baseline are calculated. They are compared to the regional prior and posterior emissions inferred in this study for years 2004 and 2010 . Units are $\mathrm{Gg} / \mathrm{yr}$. 
Table 5. HCFC-22 Consumption Baseline and Objectives That the Developing Regions Have to Reach According to the Montreal Protocol ${ }^{\mathrm{a}}$

\begin{tabular}{|c|c|c|c|c|c|c|}
\hline & \multicolumn{2}{|r|}{ 2009-2010 Average } & \multicolumn{4}{|c|}{ Objectives Based on Emission Baseline } \\
\hline & Prior & Posterior $=$ Emissions Baseline & Freeze in 2013 & $-10 \%$ in 2015 & $-35 \%$ in 2020 & $-67.5 \%$ in 2025 \\
\hline $\begin{array}{l}\text { Eastern Asia (including China, } \\
\text { India, Thailand) }\end{array}$ & $215 \pm 27$ & $185 \pm 7$ & 185 & 166 & 120 & 60 \\
\hline China & $180 \pm 24$ & $148 \pm 6$ & 148 & 146 & 96 & 48 \\
\hline Middle East & $31 \pm 3$ & $33 \pm 3$ & 33 & 30 & 21 & 11 \\
\hline Temperate South America & $30 \pm 3$ & $31 \pm 3$ & 31 & 28 & 21 & 10 \\
\hline
\end{tabular}

${ }^{\text {a }}$ Expressed in terms of emissions, as we assumed that HCFC-22 emissions mirror consumption with a potential delay. The emission baseline is defined here as the average of the 2009 and 2010 posterior emissions. Prior is for the average of the 2009 and 2010 prior emissions. Units are $\mathrm{Gg} / \mathrm{yr}$.

[26] 1. In case A, the European station Lampedusa, Italy (LMP) and the Asiatic stations Hateruma, Japan (HAT) and Ochi-ishi, Japan (COI) have been removed.

[27] 2. In case $\mathrm{B}$, the HCFC-22 prior emissions grid point error is reduced to $40 \%$ instead of $60 \%$.

[28] 3. In case $\mathrm{C}$, the HCFC-22 prior emissions grid point error is increased to $80 \%$ instead of $60 \%$.

[29] 4. In case D, the observation error (i.e., the modelobservation error) is set to $6 \mathrm{ppt}$ instead of $3 \mathrm{ppt}$.

[30] 5. In case $\mathrm{E}$, the temporal e-folding correlation length of prior error HCFC-22 emissions is set to 4 weeks instead of 8 weeks.

[31] The HCFC-22 emissions for the whole year 2007, for each case, are given for the six regions of interest in Figure 10a. These posterior regional results are further compared with the reference inversion in terms of anomalies in Figure 10b. The regional estimates of HCFC-22 emissions obtained by the different sensitivity tests are in a good agreement, even though some differences can be seen at the regional scale (i.e., from $-0.15 \%$ to $3 \%$ for Western Europe). The range of the inverted fluxes is well within the one-sigma posterior uncertainty for all regions except for the region Eastern Asia, where the scatter of the sensitivity tests is large (e.g., range of $53 \mathrm{Gg}$ ). However, it is limited to $15 \%$, in this region emitting more than $180 \mathrm{Gg} / \mathrm{yr}$.

[32] For the other regions, the largest range is observed in case A, when the European station Lampedusa, Italy (LMP) and the Asiatic stations Hateruma, Japan (HAT) and Ochiishi, Japan (COI) have been removed. This highlights the importance of observational constraints in the region Eastern Asia. Finally, it is worth noting that the difference between the regional inverted emissions in cases $\mathrm{B}$ and $\mathrm{C}$ relative to the reference inversion is small, indicating that the inversion is not very sensitive to the prior errors statistics at the scales of interest here.

\subsection{Targets and Objectives of the Montreal Protocol}

[33] The Montreal Protocol objectives are based on consumption statistics. For the developed regions, the phase-out imposed a reduction of $35 \%$ of their consumptions by 2004 and a reduction of $75 \%$ by 2010 compared to the CFC and HCFC consumptions of 1989. The phase-out has not been activated in developing countries yet, but the consumption shall have been reduced by $97.5 \%$ in 2030 compared to the average level in 2009 and 2010.

[34] An independent way to verify that these objectives are reached is to assess the effective release of HCFC-22 into the atmosphere. HCFC-22 emissions mirror consumption with a potential delay. Consequently, in the following paragraphs, we use our optimized emissions as a proxy (i) to determine whether the objectives have been reached for the developed regions and (ii) to provide a baseline for the developing regions.

[35] In developed regions, the emissions indeed started to decrease since the early 2000s: since 2000 for the EU and since 2002 for the US, as seen in Figure 7. According to the UNEP consumption statistics (UNEP, 2011), USA and Europe have reached their 2004 and 2010 reduction targets. Our inversion confirms this success (with a one-sigma range of $24-42 \mathrm{Gg} / \mathrm{yr}$ and of $8-12 \mathrm{Gg} / \mathrm{yr}$, respectively, for the US and Europe in 2010, see Table 4). The Russian emissions have increased from 2000 to 2010 but stay in the range authorized by the Montreal Protocol.

[36] Our atmospheric inversion suggests that the baselines for each of the regions Middle East, South American Temperate, and Eastern Asia are $33 \pm 3,31 \pm 3$, and $185 \pm 7 \mathrm{Gg} / \mathrm{yr}$ (including $148 \pm 6$ for China), respectively (see Table 5).

\section{Conclusion}

[37] This study aims at estimating HCFC-22 emissions for 16 years, between 1995 and 2010 at a $3.75^{\circ} \times 2.5^{\circ}$ and 8 day resolution, using an inversion system, a new gridded bottom-up inventory, and the HCFC-22 dry air mole fraction measurements from the NOAA, AGAGE, ENEA, and NIES networks.

[38] Our variational inversion framework allows highresolution estimates (grid point and 8 day), and its benefits can be seen here, revealing seasonal variations of the emissions in Eastern Asia and to a lesser extent in the US and in Middle East. Such variations are not represented in the prior annual-based inventory but are expected from the seasonality of the activity of cooling systems, including their maintenance. However, with sparse observing stations, results have not been presented at spatial resolutions smaller than subcontinents. Monitoring HCFC-22 mole fractions in the large regions South America and Russia is needed to get finer estimates in the future.

[39] Except for the region Eastern Asia, the inversion generates small increments from the prior HCFC-22 estimates, indicating that our consumption-based inventory provides a reasonable prior information. Because of the increase of emissions in developing countries, and particularly in Eastern Asia, since year 2000, global emissions have 
reached the unprecedented level of $410 \pm 9 \mathrm{Gg} / \mathrm{yr}$ in 2009 , $56 \%$ higher than the budget of $182 \pm 11 \mathrm{Gg} / \mathrm{yr}$ in 1995 . As a consequence, the Asian upcoming phase-out will be critical to decline HCFC-22 global concentrations.

[40] Finally, the inverse modeling approach offers an attractive solution for an independent evaluation of the reduction plans of emissions. Developed regions (USA, Western Europe, and Russia) appear to have reached both their 2004 and 2010 targets. The 2009-2010 baseline emissions for the developing regions South America, Middle East, and Eastern Asia are $31 \pm 3,33 \pm 3$, and $185 \pm 7 \mathrm{Gg} / \mathrm{yr}$, respectively. Our study suggests the possibility for future amendments of the Montreal Protocol to consider emissions rather than consumption statistics.

[41] Acknowledgments. We acknowledge the NOAA ESRL, Global Monitoring Division (GMD), Halocarbons and other Atmospheric Trace Species (HATS), the Advanced Global Atmospheric Gases Experiment (AGAGE), the Italian National Agency for New Technologies, Energy and Sustainable Economic Development (ENEA), and the National Institute for Environmental Studies (NIES) groups for providing HCFC-22 measurements. We thank J. W. Elkins (NOAA), S. A. Montzka (NOAA), S. O'Doherty (AGAGE), P. G. Simmonds (AGAGE), R. F. Weiss (AGAGE), P. J. B. Fraser (AGAGE), L. P. Steele (AGAGE), P. B. Krummel (AGAGE), C. Lunder (AGAGE), J. Muhle (AGAGE), S. Reimann (AGAGE) and M. K. Vollmer (AGAGE), D. Young (AGAGE), H. Mukai (NIES), T. Saito (NIES), A. Disarra (ENEA), S. Piacentino (ENEA), and S. Chiavarini (ENEA). We thank S. Barrault (Armines-ParisTech) for the fruitful discussions about the HCFC-22 inventories. Finally, we wish to thank F. Marabelle and his team for computer support at LSCE.

\section{References}

Artuso, F., P. Chamard, S. Chiavarini, A. di Sarra, D. Meloni, S. Piacentino, and D. M. Sferlazzo (2010), Tropospheric halocarbons and nitrous oxide monitored at a remote site in the Mediterranean, Atmos. Environ., 44(38), 4944-4953.

Bousquet, P., D. Hauglustaine, P. Peylin, C. Carouge, and P. Ciais (2005), Two decades of $\mathrm{OH}$ variability as inferred by an inversion of atmospheric transport and chemistry of methyl chloroform, Atmos. Chem. Phys., 5, 2635-2656, doi:10.5194/ACP-5-2635-2005.

Chevallier, F., F.-M. Breon, and P. Rayner (2007), The contribution of the Orbiting Carbon Observatory to the estimation of $\mathrm{CO}_{2}$ sources and sinks: Theoretical study in a variational data assimilation framework, J. Geophys. Res., 112, D09307, doi:10.1029/2006JD007375.

Cox, R. A, R. Atkinson, G. K. Mootrgat, A. R. Ravishankara, and H. W. Sidebottom (1995), Atmospheric degradation of halocarbon substitutes, in Scientific Assessment of Ozone Depletion: 1994, vol. 37, edited by Albritton, D. L., R. T. Watson, and P. J. Aucamp, pp. 12.1-12.23, World Meteorol. Organ., Geneva.

Gilbert, J., and C. Lemaréchal (1989), Some numerical experiments with variable-storage quasi-Newton algorithms, Math. Program., 45, 407-435.

Hauglustaine, D. A., F. Hourdin, L. Jourdain, M.-A. Filiberti, S. Walters, J.-F. Lamarque, and E. Holland (2004), Interactive chemistry in the Laboratoire de Meteorologie Dynamique general circulation model: Description and background tropospheric chemistry evaluation, J. Geophys Res., 109, D04314, doi:10.1029/2003JD003957.

Hourdin, F., I. Musat, S. Bony, P. Braconnot, and F. Codron (2006), The LMDZ4 general circulation model: Climate performance and sensitivity to parametrized physics with emphasis on tropical convection, Clim Dyn., 27, 787-813, doi:10.1007/S00382-006-0158-0.

Kaminski, T., P. J. Rayner, M. Heimann, and I. G. Enting (2001), On aggregation errors in atmospheric transport inversions, J. Geophys. Res., $106,4703-4715$.

Krol, M., and J. Lelieveld (2003), Can the variability in tropospheric $\mathrm{OH}$ be deduced from measurements of 1,1,1-trichloroethane (methyl chloroform)? J. Geophys. Res., 108(D3), 4125, doi:10.1029/2002JD002423.

McCulloch, A., P. M. Midgley, and P. Ashford (2003), Releases of refrigerant gases (CFC-12, HCFC-22 and HFC-134a) to the atmosphere, Atmos. Environ., 37, 889-902, doi:10.1016/S1352-2310(02)00975-5.

McCulloch, A. (2005), Determination of comparative HCFC and HFC emission profiles for the foam and refrigeration sectors until 2015, Part 3: Total emissions and global atmospheric concentrations, Report, U.S. Environ. Prot. Agency, Washington, D. C. [Available at: http://www epa.gov/ozone/snap/emissions/downloads/FoamEmissionProfiles_Part3. pdf.].

Miller, B. R., J. Huang, R. F. Weiss, R. G. Prinn, and P. J. Fraser (1998), Atmospheric trend and lifetime of chlorodifluoromethane (HCFC-22) and the global tropospheric $\mathrm{OH}$ concentration, J. Geophys. Res., 103(D11), 13,237-13,248, doi:10.1029/98JD00771.

Montzka, S. A., R. C. Myers, J. H. Butler, J. W. Elkins, and S. O. Cummings (1993), Global tropospheric distribution and calibration scale of HCFC-22, Geophys. Res. Lett., 20(8), 703-706, doi:10.1029/ 93GL00753.

Montzka, S. A., B. D. Hall, and J. W. Elkins (2009), Accelerated increases observed for hydrochlorofluorocarbons since 2004 in the global atmosphere, Geophys. Res. Lett., 36, L03804, doi:10.1029/2008GL036475.

Montzka, S. A., et al. (2011), Ozone-depleting substances (ODSs) and related chemicals, in Scientific Assessment of Ozone Depletion: 2010, Global Ozone Research and Monitoring Project Report No. 52, World Meteorol. Organ., Geneva, Switzerland, Chapter 1, 41-150.

O'Doherty, S., et al. (2004), Rapid growth of hydrofluorocarbon 134a and hydrochlorofluorocarbons $141 \mathrm{~b}, 142 \mathrm{~b}$ and 22 from AGAGE observations at Cape Grim, Tasmania and Mace Head, Ireland, J. Geophys. Res., 109, D06310, doi:10.1029/2003JD004277.

Pison, I., P. Bousquet, F. Chevallier, S. Szopa, and D. Hauglustaine (2009), Multi-species inversion of $\mathrm{CH}_{4}, \mathrm{CO}$ and $\mathrm{H}_{2}$ emissions from surface measurements, Atmos. Chem. Phys., 9, 5281-5297.

Prinn, R. G. et al. (2001), Evidence for substantial variations of atmospheric hydroxyl radicals in the past two decades, Science, 292, 1882-1888.

Sander, S. P., et al. (2011), Chemical Kinetics and Photochemical Data for Use in Atmospheric Studies, Evaluation No. 17, JPL Publication 10 - 6 , Jet Propulsion Laboratory, Pasadena, http://jpldataeval.jpl.nasa.gov.

Saikawa, E., et al. (2012), Global and regional estimates for HCFC22, Atmos. Chem. Phys., 12, 10,033-10,050, doi:10.5194/ACP-1210033-2012.

Stohl, A., et al. (2009), An analytical inversion method for determining regional and global emissions of greenhouse gases: Sensitivity studies and application to halocarbons, Atmos. Chem. Phys., 9, $1597-1620$.

Stohl, A., et al. (2010), Hydrochlorofluorocarbon and hydrofluorocarbon emissions in East Asia determined by inverse modeling, Atmos. Chem. Phys., 10, 3545-3560.

Vollmer, M. K., et al. (2009), Emissions of ozone-depleting halocarbons from China, Geophys. Res. Lett., 36, L15823, doi:10.1029/ 2009GL038659.

U.N. Environment Programme, (2007), Report of the 19th Meeting of the Parties to the Montreal Protocol on Substances that Deplete the Ozone Layer, Technical Report, Montreal, Canada.

Yokouchi, Y., S. Taguchi, T. Saito, Y. Tohjima, H. Tanimoto, and H. Mukai (2006), High-frequency measurements of HFCs at a remote site in east Asia and their implications for Chinese emissions, Geophys. Res. Lett., 33, L21814, doi:10.1029/2006GL026403. 